\title{
Gram-negative bacilli in burns
}

\author{
BRENDA DAVIS, H. A. LILLY, AND E. J. L. LOWBURY \\ From the M.R.C. Industrial Injuries and Burns Research Unit, Birmingham Accident Hospital
}

SYNOPSIS In a period of two years, 865 strains of Gram-negative bacilli other than Pseudomonas aeruginosa isolated from burns were identified by a range of tests. The commonest species were 용 Proteus mirabilis, Escherichia coli, and Enterobacter cloacae. Many strains of Klebsiella aerogenes, i Enterobacter aerogenes, and Bacterium anitratum were also found.

A large proportion of the strains were tested for sensitivity to nalidixic acid, ampicillin, kana- $\overbrace{5}$ mycin, chloramphenicol, tetracycline, and carbenicillin, and smaller numbers of strains were tested $\stackrel{+}{\circ}$ for sensitivity to cephaloridine, polymyxin, streptomycin, sulphadiazine, sulfamylon, and tri- $\stackrel{ }{\triangle}$ methoprim. The proportion of strains sensitive and resistant to different antibacterial agents varied $z$ widely with species of bacteria. A large proportion of the strains of $E$. coli and $P$. mirabilis were resistant to ampicillin, which was much used in treatment; resistance appeared least often towards nalidixic acid, kanamycin, trimethoprim, and gentamicin. Multiple resistance occurred less often $\Phi$ among strains of $E$. coli than among Klebsiella spp, Enterobacter spp, and P. mirabilis.

Phage and serological typing of Ps. aeruginosa showed that most infections of burns with this organism were due to strains previously found in other patients in the same ward. Taken with other evidence, this supported the view that most infections with Ps. aeruginosa were not acquired from the patient's own flora but from sources in the hospital environment.

Gram-negative rods are known to be among the commonest types of bacteria isolated from burns (Colebrook, Clark, Gibson, and Todd, 1944; Langohr, Owen, and Cope, 1947; Jackson, Lowbury, and Topley, 1951; Liedberg, Reiss, Kuhn, Amspacher, and Artz, 1955). The special importance of Pseudomonas aeruginosa has been widely reported (eg, Jackson et al, 1951; Markley, Gurmendi, Chavez, and Bazan, 1957; Tumbusch, Vogel, Butkiewicz, Graber, Larson, and Mitchell, 1961; Jones, Jackson, and Lowbury, 1966), but other Gram-negative bacilli are also commonly found in burns. Some of these are potentially important human pathogens, especially in the urinary and respiratory tracts, and occasionally they are the cause of invasive infection and bacteraemic shock. Infection with these organisms is reported to have increased during the era of antibiotics (Finland, 1960; Watt and Okubadejo, 1967). Following the successful control of infection with Ps. aeruginosa, other Gram-negative bacilli have been a commoner cause than Ps. aeruginosa of septicaemia and death in severely burned patients (Cason and Lowbury, 1968).

$P$ s. aeruginosa forms a homogeneous and easily identified 'cluster' of bacteria (Liston, Wiebe, and Colwell, 1963) and Proteus can be subdivided by a Received for publication 5 August 1969. few simple tests into species, but the identification of other Gram-negative bacilli requires more elaborate study and the conclusions are sometimes uncertain. For this reason strains isolated on routine examination of burn or wound flora have commonly been grouped together as 'coliform bacilli'.

We report here the identification and antibiotic sensitivity patterns of a series of Gram-negative bacilli isolated from burns of patients in the hospital $\delta$ over a period of two years; this series includes strains of Proteus spp but not of Ps. aeruginosa, the incidence of which in the same period, under various con- $>$ ditions of treatment, has been reported elsewhere (Cason, Jackson, Lowbury, and Ricketts, 1966; N Lowbury and Jackson, 1968). We include, however, a note on the types of Ps. aeruginosa present in the burns wards during the period of study, since a large number of these but not of other Gram-negative bacilli were typed, allowing some discussion on the 0 probable sources and routes of transfer of $P s$. aeruginosa.

\section{MATERIALS AND METHODS}

SOURCE OF BACTERIAL STRAINS Burns were examined for bacterial fiora by methods described elsewhere (Lowbury, 1960; Brown and Lowbury, 1965; Cason et al, 1966). 
Swabs moistened with peptone water were used for sampling, and samples were taken on admission, at all changes of dressings and operations, and daily from burns treated by the exposure method.

METHODS OF ISOLATION Swabs were inoculated on horse blood agar made with infusion broth, containing concentrated (4\%) New Zealand agar to prevent swarming of Proteus, also on improved cetrimide agar (Brown and Lowbury, 1965), and into Robertson's cooked meat medium. After overnight incubation at $37^{\circ} \mathrm{C}$, the blood agar plates were examined for aerobic growth and one colony of every colonial form was picked for confirmatory tests and for morphological examination of a Gramstained film; a similar examination was made of subcultures from cooked meat medium to blood agar.

A rough sorting of Gram-negative bacilli was made by examining blood agar and cetrimide agar plates under ultraviolet irradiation for growth and fluorescence (Lowbury, Lilly, and Wilkins, 1962) and by tests for oxidase production (Kovacs, 1956); fluorescent, oxidaseproducing growth was further examined for characters of Ps. aeruginosa (Brown and Lowbury, 1965). Urease tests were made for presumptive recognition of Proteus spp. One isolate of every colony form of Gram-negative bacilli from each patient per week was selected for further examination to determine the species of Proteus and, when possible, the genus or the genus and species of other types of Gram-negative bacilli.

METHODS OF IDENTIFICATION Colonies of Gram-negative bacilli picked from blood agar plates were subcultured to a second blood agar plate and to a spot-plate of cetrimide agar. Strains which failed to grow at $37^{\circ} \mathrm{C}$ or to give yellow-green fluorescence on cetrimide agar and which gave a negative oxidase reaction, that is, those which were not classed as $P$ s. aeruginosa or presumptive $P s$. aeruginosa, were examined, in subcultures from colonies on blood agar, by the methods and identified according to the criteria described by Cowan and Steel $(1961,1965)$; similar tests were used for oxidase-producing strains which failed to grow on cetrimide agar or to produce pigments typical of Ps. aeruginosa.

Tests were made for the following characters: (1) urease production in six hours on Christensen's medium; (2) phenyl alanine deaminase (PPA) and malonate utilization, using the combined malonate-phenyl alanine medium of Shaw and Clarke (1955); (3) gelatinase production, using gelatin-charcoal discs (Oxoid) incubated for seven to 10 days (Kohn, 1953); (4) $\mathrm{H}_{2} \mathrm{~S}$ production by lead acetate papers over peptone water cultures examined after 48 hours; (5) indole production by the use of ether and Ehrlich's reagent; (6) fermentation of glucose, mannite, maltose, dulcitol, and sucrose in two to three days; (7) oxidation-fermentation test (Hugh and Leifson, 1953); (8) gluconate oxidation (Shaw and Clarke, 1955); (9) citrate utilization (Koser's and Simmons' methods); (10) motility, by hanging drop and by stab inoculation in semi-solid agar; (11) methyl red and Voges-Proskauer reactions (Barritt's method) after two to three days' incubation at $37^{\circ} \mathrm{C}$; (12) growth in $\mathrm{KCN}$ broth (Rogers and Taylor, 1961); (13) nitrate reduction in four to seven days; and (14) arginine, lysine, and ornithine decarboxylase tests (Møller, 1955).

A composite table, based largely on the tables of Cowan and Steel (1961, 1965), was used for identification of strains. Those classified as Proteus spp (including Providencia or Proteus inconstans) because they gave a strong urease reaction on Christensen's medium in six hours were allocated to species on the basis of findings in tests 1 to 6.

ANTIBIOTIC SENSITIVITY TESTS Strains were tested by a ditch plate diffusion method that has been used in this Unit for many years (Topley, Lowbury, and Hurst, 1951), with a sensitive control organism (Staph. aureus, Oxford strain) on each plate; in tests with nalidixic acid a sensitive strain of $E$. coli was used as the control. Sensitivity to ampicillin, carbenicillin, cephaloridine, streptomycin, kanamycin, gentamicin, tetracycline, chloramphenicol, nalidixic acid, sulphadiazine, and trimethoprim was tested by this method. Ampicillin, carbenicillin, and sulphadiazine were included in the agar of the ditch at $100 \mu \mathrm{g}$ per $\mathrm{ml}$, trimethoprim lactate at $10 \mu \mathrm{g}$ per $\mathrm{ml}$ (prepared with a solution heated to $60^{\circ}$ to $70^{\circ} \mathrm{C}$ ), and the other agents at $50 \mu \mathrm{g}$ per $\mathrm{ml}$. A loopful of overnight broth culture was streaked across the plate at right angles to the ditch; the culture was undiluted except in tests with sulphadiazine and trimethoprim, for which a 1 in 250 dilution was used. Ditch plates were examined after 18 hours' incubation at $37^{\circ} \mathrm{C}$ and the result was assessed as 'sensitive' (zone of inhibition similar to that of control), 'moderately sensitive' (reduced zone of inhibition), and 'resistant' (growth up to or across the ditch).

To assess the significance of these tests and adjust antibiotic concentration in the ditch where necessary, a selection of strains of each identified type and of some unidentified species were tested for sensitivity to these agents also by a tube dilution method (or, in the case of sulphadiazine and of trimethoprim, by a plate dilution method), with an inoculum in the tube dilution test of one drop of a 1 in 1,000 dilution and in the plate dilution test of a small loopful of 1 in 250 dilution of an overnight broth culture.

Because of the unsuitability of diffusion tests for sensitivity to polymyxin (Bushby, 1955), strains were tested for sensitivity to this antibiotic by a plate dilution test. The same method was used for tests of a proportion of the strains with sulfamylon (p. amino methyl benzene sulphonamide hydrochloride). The 'sensitivity' was assessed in relation to possible value in therapy for infections of soft tissues by antibiotics given orally or parenterally.

With the exception of trimethoprim and sulphadiazine, antibacterial agents were added to nutrient agar for plate dilution tests and to peptone water agar for ditch plate tests. Trimethoprim and sulphadiazine hydrochloride were added, for these tests, to lysed blood agar with infusion broth.

Some strains were tested for penicillinase production, using benzyl penicillin, ampicillin, and carbenicillin as substrates; $2 \mathrm{ml}$ amounts of 24-hour broth cultures were incubated at $37^{\circ} \mathrm{C}$ with $1 \mathrm{ml}$ of an aqueous solution of 
TABLE I

IDENTIFICATION OF 865 STRAINS OF GRAM-NEGATIVE BACILLI (EXCLUDING Ps. aeruginosa) ISOLATED FROM $\stackrel{\overline{0}}{2}$ BURNS (SEPTEMBER 1965 TO SEPTEMBER 1967)

\begin{tabular}{|c|c|c|c|c|c|}
\hline Organism & No. of Strains & $\begin{array}{l}\text { Percentage of } \\
\text { Total Strains }\end{array}$ & Organism & No. of Strains & $\begin{array}{l}\text { Percentage of } \\
\text { Total Strains }\end{array}$ \\
\hline Proteus spp & & & Enterobacter cloacae & 119 & $13 \cdot 8$ \\
\hline P. mirabilis & 280 & $32 \cdot 4$ & Enterobacter aerogenes & 54 & $6 \cdot 2$ \\
\hline P. morganii & 17 & $2 \cdot 0$ & Enterobacter spp & 6 & $0 . \overline{7}$ \\
\hline P. vulgaris & 10 & $1 \cdot 2$ & Klebsiella aerogenes & 58 & $6 \cdot 7$ \\
\hline P. inconstans (Providencia) & 38 & $4 \cdot 4$ & Bacterium anitratum & 37 & $4 \cdot 3$ \\
\hline Unclassified Proteus strains & 15 & $1 \cdot 7$ & Serratia & 14 & $1 \cdot 6$ \\
\hline & & & Alkalescens dispar & 14 & 1.6 \\
\hline Other Gram-negative bacilli & & & Citrobacter & 9 & $1 \cdot 0$ \\
\hline ('coliform bacilli') & & & Alcaligenes & 5 & 0.6 \\
\hline Escherichia coli & 153 & $17 \cdot 7$ & Unclassified coliform bacilli & 36 & $4 \cdot 2$ \\
\hline
\end{tabular}

TABLE IIa

SENSITIVITY TO SEVEN ANTIBIOTICS BY DITCH PLATE TEST ON 730 STRAINS OF GRAM-NEGATIVE BACILLI FROM BURNS (SEPTEMBER 1965 TO SEPTEMBER 1967)

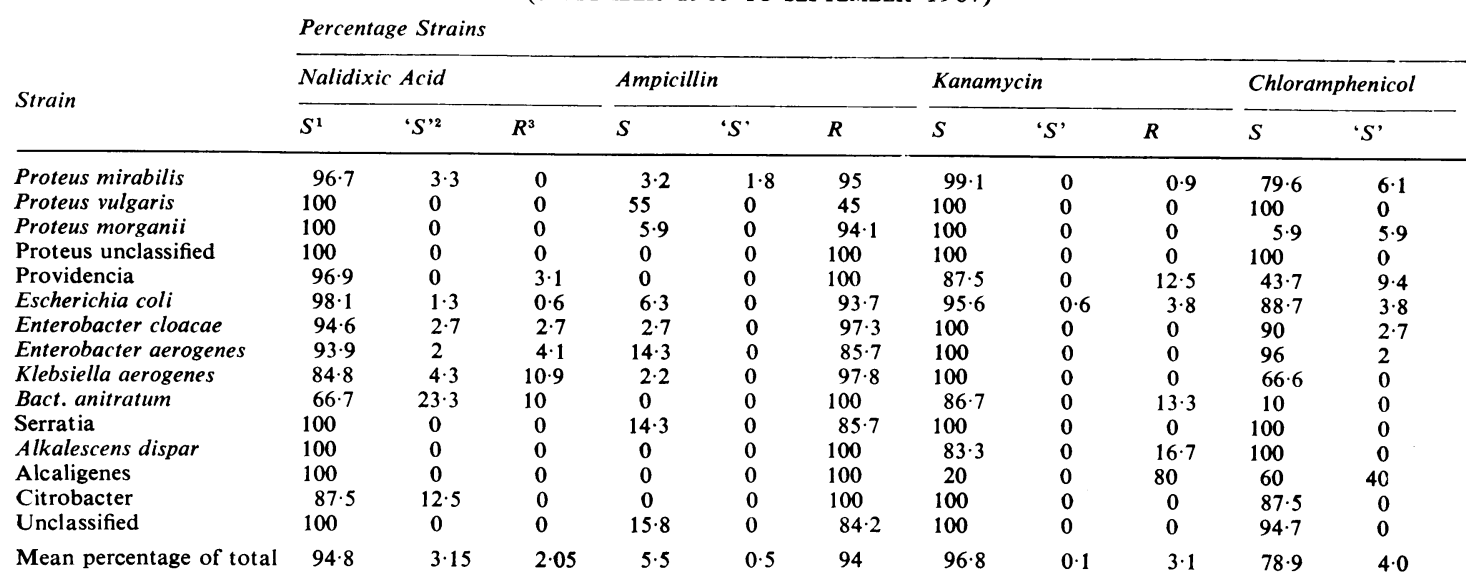

${ }^{1} S=$ sensitive, ${ }^{2} S$ ' $x$ moderately sensitive, ${ }^{3} R=$ resistant

benzyl penicillin (100 units), ampicillin $(100 \mu \mathrm{g})$, and carbenicillin $(100 \mu \mathrm{g})$. After one and a half hours the mixtures were transferred to Heatley cylinders on plates seeded with a 1 in 1,000 dilution of a broth culture of the Oxford strain of Staph. aureus. Absence or reduction of zones of inhibition around cylinders after overnight incubation of the plates was taken to indicate inactivation of the antibiotic by a penicillinase.

TYPING OF Ps. aeruginosa Many strains of Ps. aeruginosa were typed by phage and serological methods at the Central Public Health Laboratory, Colindale, using techniques described elsewhere by Thom (see Lowbury, Thom, Lilly, Babb, and Whittall, 1969).

\section{RESULTS}

Table I shows the results of identification of a series of 865 strains of Gram-negative bacilli, excluding Ps. aeruginosa, isolated from burns in this hospital between September 1965 and September 1967.
Proteus was the genus most frequently isolated, and the commonest species, $P$. mirabilis, was more common than any of the other Gram-negative bacilli. Next in frequency was Escherichia coli. Only $51(5.9 \%)$ of the strains (including 15 described as Proteus spp) could not be classified.

Table IIa shows the proportion of 730 of the strains listed in Table I which were sensitive, moderately of sensitive, and resistant to seven antibiotics or $\tilde{O}$ chemotherapeutic agents by ditch-plate tests. The N same data in respect of smaller numbers of four 0 other antibiotics are shown in Table IIb. The interpretation of these tests is shown in Table III, $\frac{\bar{\Phi}}{\Phi}$ which summarizes the results of sensitivity tests done $\stackrel{?}{+}$ in parallel by ditch plate and tube dilution methods 7 on a large number of strains, including a representative sampling of each genus or species; the range of minimum inhibitory concentrations (MIC) corresponding to ditch plate readings $\mathbf{S}$, 'S', and $\mathbf{R}$ was narrower in relation to individual species tested 
than in the collective results shown in Table III. A larger proportion of strains was sensitive to kanamycin, nalidixic acid, trimethoprim, and gentamicin than to the other agents; the lowest proportion of sensitive results was obtained with ampicillin. Different species varied considerably in their sensitivity patterns; eg, the majority of $P$. mirabilis were sensitive to cephaloridine, but the majority of $P$. morganii were resistant to this agent. Sensitivity to tetracycline was found in $50 \%$ of $E$. coli strains, but in only $4 \%$ of the strains of Enterobacter aerogenes.

Cultures on nutrient agar slopes of 125 strains of $E$. coli and 83 strains of $P$. mirabilis from this series were stored for 15 months at room temperature and then tested again for sensitivity to ampicillin. Of the strains of $E$. coli, $117(94 \%)$ were resistant in the first test, but only $51(41 \%)$ were resistant in the second test; of the $P$. mirabilis strains, $79(95 \%)$ were resistant in the first test, and $62(75 \%)$ were resistant in the second test. A series of more recent isolates of $E$. coli (24) and P. mirabilis (21) from the Burns Unit were tested and retested after two months' storage at room temperature; $11(46 \%)$ of the $E$. coli strains and $16(76 \%)$ of the $P$. mirabilis strains were resistant at the time of sampling; after two months' storage $10(42 \%)$ of $E$. coli and $15(71 \%)$ of $\boldsymbol{P}$. mirabilis were resistant to ampicillin. The anti-

TABLE IIa-continued

SENSITIVITY TO SEVEN ANTIBIOTICS BY DITCH PLATE TEST ON 730 STRAINS OF GRAM-NEGATIVE BACILLI FROM BURNS (SEPTEMBER 1965 TO SEPTEMBER 1967)

\begin{tabular}{|c|c|c|c|c|c|c|c|c|c|c|}
\hline \multirow[b]{3}{*}{$\boldsymbol{R}$} & \multicolumn{9}{|c|}{ Percentage Strains } & \multirow[t]{3}{*}{ Number of Strains } \\
\hline & \multicolumn{3}{|c|}{ Tetracycline } & \multicolumn{3}{|c|}{ Carbenicillin } & \multicolumn{3}{|c|}{ Gentamicin } & \\
\hline & $S$ & $' s '$ & $\boldsymbol{R}$ & $S$ & $' S '$ & $\boldsymbol{R}$ & $S$ & $' S$ ' & $\boldsymbol{R}$ & \\
\hline $14 \cdot 3$ & $83 \cdot 3$ & 0.5 & $16 \cdot 2$ & 94.9 & 0 & $5 \cdot 1$ & $99 \cdot 5$ & 0.5 & 0 & 216 \\
\hline 0 & $36 \cdot 3$ & 0 & $63 \cdot 7$ & 55 & 0 & 45 & 100 & 0 & 0 & 11 \\
\hline $88 \cdot 2$ & 52.9 & $11 \cdot 8$ & $35 \cdot 3$ & $94 \cdot 1$ & 0 & 5.9 & $94 \cdot 1$ & $5 \cdot 9$ & 0 & 17 \\
\hline 0 & 50 & 0 & 50 & 100 & 0 & 0 & 100 & 0 & 0 & 2 \\
\hline 46.9 & $6 \cdot 3$ & $3 \cdot 1$ & $90 \cdot 6$ & $93 \cdot 7$ & $6 \cdot 3$ & 0 & 62.5 & 25 & $12 \cdot 5$ & 32 \\
\hline $7 \cdot 5$ & 50 & $5 \cdot 1$ & 44.9 & $76 \cdot 1$ & $1 \cdot 3$ & $22 \cdot 6$ & $99 \cdot 4$ & 0.6 & 0 & 159 \\
\hline $7 \cdot 3$ & $35 \cdot 5$ & 9 & 55.5 & $86 \cdot 4$ & $2 \cdot 7$ & 10.9 & $98 \cdot 2$ & 0.9 & 0.9 & 110 \\
\hline 2 & $4 \cdot 1$ & $40 \cdot 8$ & $55 \cdot 1$ & $77 \cdot 5$ & 2 & $20 \cdot 5$ & $97 \cdot 9$ & 0 & $2 \cdot 1$ & 49 \\
\hline 33.4 & $52 \cdot 2$ & $6 \cdot 5$ & $41 \cdot 3$ & $15 \cdot 2$ & 0 & $84 \cdot 8$ & $97 \cdot 8$ & $2 \cdot 2$ & 0 & 46 \\
\hline 90 & $6 \cdot 7$ & $3 \cdot 3$ & 90 & $63 \cdot 4$ & $23 \cdot 3$ & $13 \cdot 3$ & $83 \cdot 4$ & $6 . \overline{6}$ & 10 & 30 \\
\hline 0 & $28 \cdot 6$ & 0 & $71 \cdot 4$ & $85 \cdot 7$ & 0 & $14 \cdot 3$ & 100 & 0 & 0 & 14 \\
\hline 0 & 75 & 0 & 25 & 50 & 0 & 50 & 100 & 0 & 0 & 12 \\
\hline 0 & 0 & 0 & 100 & 100 & 0 & 0 & 100 & 0 & 0 & 5 \\
\hline $12 \cdot 5$ & $12 \cdot 5$ & 0 & $87 \cdot 5$ & 50 & $12 \cdot 5$ & $37 \cdot 5$ & 100 & 0 & 0 & 8 \\
\hline $5 \cdot 3$ & $42 \cdot 1$ & $10 \cdot 5$ & $47 \cdot 4$ & $68 \cdot 4$ & 10.5 & $21 \cdot 1$ & 100 & 0 & 0 & 19 \\
\hline $17 \cdot 1$ & $52 \cdot 6$ & $4 \cdot 1$ & $43 \cdot 3$ & $79 \cdot 4$ & $2 \cdot 7$ & $17 \cdot 9$ & 96.7 & $2 \cdot 1$ & $1 \cdot 2$ & 730 \\
\hline
\end{tabular}

TABLE IIb

SENSITIVITY TO FOUR ANTIBIOTICS BY DITCH PLATE TEST ON STRAINS OF GRAM-NEGATIVE BACILLI (SEPTEMBER 1965 TO SEPTEMBER 1967)

Percentage Strains

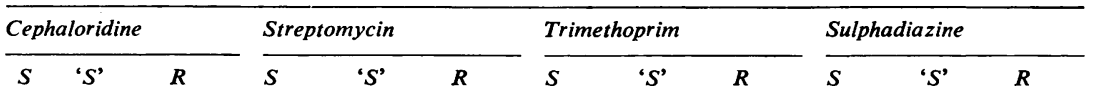
Total Strains Tested with
Cephal- Trimeth- Sulphtioridine oprim and azine Streptomycin

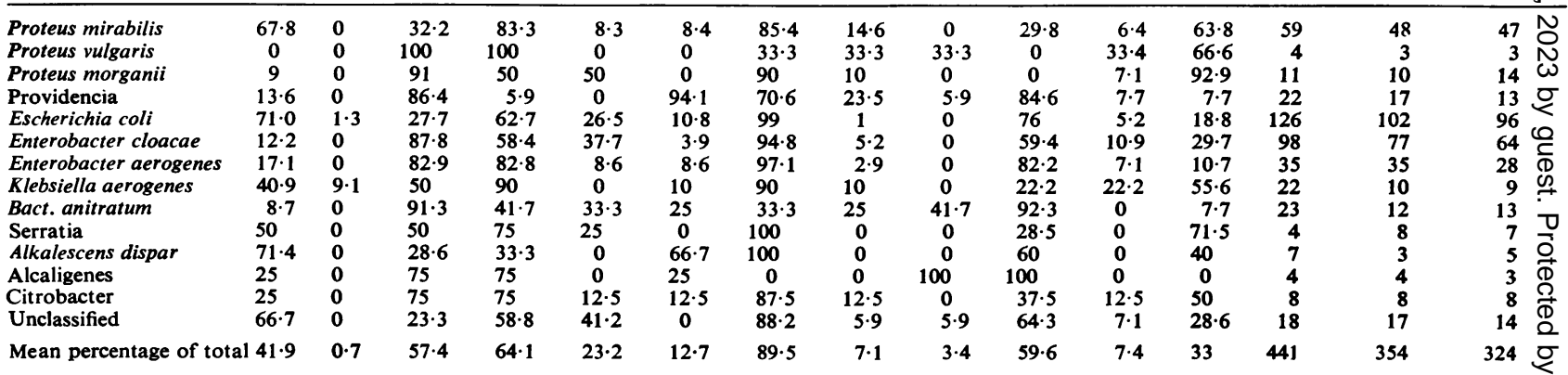


TABLE III

ANTIBIOTIC SENSITIVITY OF GRAM-NEGATIVE BACILLI BY DITCH PLATE AND TUBE DILUTION TESTS ${ }^{1}$

\begin{tabular}{|c|c|c|c|c|}
\hline \multirow[t]{2}{*}{ Antibiotic } & \multicolumn{3}{|c|}{$\begin{array}{l}\text { Minimal Inhibitory Concentrations } \\
(\mu \mathrm{g} / \mathrm{ml}) \text { of Antibiotics for Strains } \\
\text { Shown in Ditch Plate as }\end{array}$} & \multirow[t]{2}{*}{$\begin{array}{l}\text { Number of } \\
\text { Strains } \\
\text { Tested }\end{array}$} \\
\hline & $S$ & $' S '$ & $\boldsymbol{R}$ & \\
\hline Ampicillin & $1-16$ & $16-32$ & $(8)^{2} 16-512$ & 180 \\
\hline Carbenicillin ${ }^{3}$ & $6 \cdot 25-16$ & $8-32$ & $16-512$ & 180 \\
\hline Cephaloridine & $1-16$ & $8-32$ & $16->512$ & 180 \\
\hline Kanamycin & $0 \cdot 5-16$ & 32 & $16-64$ & 180 \\
\hline Gentamicin & $0 \cdot 25-2$ & $1-32$ & $4-64$ & 180 \\
\hline Tetracycline & $2-32$ & $16-64$ & $32-256$ & 180 \\
\hline \multirow{6}{*}{$\begin{array}{l}\text { Chloram- } \\
\text { phenicol } \\
\text { Nalidixic acid } \\
\text { Streptomycin } \\
\text { Trimethoprim } \\
\text { Sulphadiazine }\end{array}$} & & & & \\
\hline & $1-16$ & $8-32$ & $32-512$ & 180 \\
\hline & $0 \cdot 25-16$ & $8-32$ & $32-64$ & 180 \\
\hline & $4-16$ & $8-32$ & 64-512 & 97 \\
\hline & $0 \cdot 5-10$ & $10-20$ & $20-500$ & 49 \\
\hline & $2 \cdot 5-50$ & $25-100$ & $150->500$ & 47 \\
\hline $\mathbf{S}=$ Sensitive & \multicolumn{4}{|c|}{ 'S' = Moderately sensitive } \\
\hline
\end{tabular}

${ }^{1}$ The results are based on tests made on strains representing 14 genera or species and a group of unclassified organisms.

${ }^{2}$ Only in Alcaligenes and Alkalescens dispar.

${ }^{3}$ Carbenicillin has been used in the treatment of pseudomonas infections, which were found $S$ and ' $S$ ' by the ditch test when MIC was $32 \mu \mathrm{g} / \mathrm{ml}$ or less, and $64 \mu \mathrm{g} / \mathrm{ml}$ respectively.

biotic was commonly used in the treatment of patients in the Burns Unit. A large proportion of the strains tested were sensitive to trimethoprim; the proportions of strains sensitive to sulphadiazine and to streptomycin were considerably smaller. Trimethoprim had not yet been used, and streptomycin and sulphadiazine were rarely used in the Unit.

SULFAMYLON SENSITIVITY Because of its reported value as a topical prophylactic agent (Lindberg, Moncrief, Switzer, Order, and Mills, 1965; Lowbury and Jackson, 1969), sulfamylon was included in these tests. Table IV shows the MIC of sulfamylon hydrochloride for 389 strains of Gram-negative

\section{TABLE IV}

SENSITIVITY OF 389 GRAM-NEGATIVE BACILLI TO SULFAMYLON HYDROCHLORIDE

Organism Number of Strains Showing MIC (mg per ml) of

$\begin{array}{llllllll}\text { Total } & 0.2 & 0.5 & 1 & 2 & 5 & 10 & 20\end{array}$
Strains

\begin{tabular}{|c|c|c|c|c|c|c|c|c|}
\hline $\begin{array}{l}\text { Proteus mirabilis } \\
\text { Proteus vulgaris }\end{array}$ & $\begin{array}{r}54 \\
3\end{array}$ & & & & & 3 & 19 & $\begin{array}{r}32 \\
3\end{array}$ \\
\hline Proteus morganii & 8 & & 1 & & 2 & 2 & 3 & \\
\hline Providencia & 19 & & & & & 2 & 10 & 7 \\
\hline Ent.liquifaciens & 1 & & & & & & & 1 \\
\hline E. coli & 116 & 1 & & 2 & & 3 & 62 & 48 \\
\hline Ent. cloacae & 89 & & & & & 36 & 46 & 7 \\
\hline Ent. aerogenes & 39 & & & & & 11 & 22 & 6 \\
\hline Kleb. aerogenes & 6 & & & & & 1 & 4 & 1 \\
\hline Bact. anitratum & 11 & & 2 & 1 & 3 & 1 & 3 & 1 \\
\hline Serratia & 8 & & & & & 3 & & 5 \\
\hline Alk. dispar & 3 & & & & & & 3 & \\
\hline Alcaligenes & 5 & 2 & & 1 & & 2 & & \\
\hline Citrobacter & 9 & & & & & & 7 & 2 \\
\hline Unclassified & 18 & & 1 & 3 & 1 & 8 & 3 & 2 \\
\hline
\end{tabular}

bacilli. All the strains were sensitive to $20 \mathrm{mg}$ per milliiitre or less of the compound, which was lower than the concentration used for local application (100 $\mathrm{mg}$ per gram), though in many strains the margin was not great.

POLYMYXIN SENSITIVITY Table $\mathrm{V}$ shows the results of plate dilution sensitivity tests with polymyxin. Strains of Proteus spp (including Providencia) and Serratia were usually resistant (strains not inhibited by $12.8 \mu \mathrm{g}$ colistin sulphomethate per $\mathrm{ml}$; see Bushby, 1955). The majority of the strains of other species were sensitive.

PENICILLINASE PRODUCTION AND RESISTANCE TO ANTIBIOTICs Many strains of Proteus spp, Escherichia, and other coliform bacilli were sensitive to carbenicillin but resistant to ampicillin. Since both ampicillin and carbenicillin are known to be inactivated by penicillinases, a selection of strains was tested for diffusible penicillinase production, using benzyl penicillin, carbenicillin, and ampicillin as the test subtrates, and for sensitivity to these antibiotics. From these tests it was hoped to obtain evidence about the association of penicillinase production with resistance, about the similarity of patterns of inactivation of the three penicillins by bacterial enzymes, and about the frequency of intrinsic resistance.

Table VI shows the results of these tests. Ampicillinase and carbenicillinase activity were found in the same four strains, which were also highly resistant to both antibiotics as well as to benzyl penicillin. A number of other strains which were sensitive to ampicillin and carbenicillin inactivated benzylpenicillin and were resistant to it. Several strains which did not inactivate ampicillin or carbenicillin had intrinsic resistance to ampicillin but not to carbenicillin. One strain of $E$. coli was more resistant to carbenicillin than to ampicillin, and one strain (of Serratia) which did not inactivate any of the three penicillins was more sensitive to benzyl penicillin and carbenicillin than to ampicillin.

MULTIPLE RESISTANCE Strains of the commonest species which were tested for sensitivity to cephaloridine (see Table IIb) were analysed for multiple resistance to two or more of the eight antibacterial agents listed in Table III (see Table VII). E. coli was most often resistant to one agent only, but the other species were more often resistant to two or three agents; the resistance patterns of these strains are shown in Table VII. The great majority of strains showing resistance to one antibiotic were resistant to ampicillin. 
TABLE V

SENSITIVITY OF 295 GRAM-NEGATIVE BACILLI TO COLISTIN SULPHOMETHATE

\begin{tabular}{|c|c|c|c|c|c|c|c|c|c|}
\hline \multirow[t]{2}{*}{ Organism } & \multirow[t]{2}{*}{ Total Strains } & \multicolumn{8}{|c|}{ Number of Strains Showing $M I C(\mu \mathrm{g} / \mathrm{ml})$ of } \\
\hline & & 0.05 & $0 \cdot 2$ & 0.8 & $3 \cdot 2$ & $6 \cdot 4$ & $12 \cdot 8$ & $25 \cdot 6$ & $>25 \cdot 6$ \\
\hline Proteus mirabilis & 45 & & & 1 & 3 & 1 & & 23 & 17 \\
\hline Proteus vulgaris & 2 & & & & & & 1 & 1 & \\
\hline Proteus morganii & 7 & & & & 1 & 2 & & 2 & 2 \\
\hline Providencia & 14 & & & & & & & 5 & 9 \\
\hline E. coli & 86 & & 1 & 25 & 46 & 6 & & 1 & 7 \\
\hline Ent. cloacae & 66 & & & 18 & 30 & 8 & & 1 & 9 \\
\hline Ent. aerogenes & 25 & & & 8 & 13 & 2 & & 1 & 1 \\
\hline Kleb. aerogenes & 9 & & & 1 & 5 & 1 & 1 & 1 & \\
\hline Bact. anitratum & 8 & & 1 & & 4 & 2 & & 1 & \\
\hline Serratia & 8 & & & & & & 1 & 2 & 5 \\
\hline Alk. dispar & 3 & 1 & & 1 & 1 & & & & \\
\hline Alcaligenes & 4 & & & & 2 & 1 & & 1 & \\
\hline Citrobacter & 7 & 1 & & 3 & 3 & & & & \\
\hline Unclassified & 11 & 1 & & 3 & 3 & & & 2 & 2 \\
\hline
\end{tabular}

TABLE VI

PENICILLINASE PRODUCTION AND SENSITIVITY OF GRAM-NEGATIVE BACILLI TO BENZYLPENICILLIN, AMPICILLIN AND CARBENICILLIN

Benzylpenicillin

MIC Ditch Plate Inactivation

$(\mu \mathrm{g} / \mathrm{ml}) \quad$ Result by Strain

\begin{tabular}{lll} 
Ampicillin & \\
\hline MIC & $\begin{array}{l}\text { Ditch Plate } \\
\text { Result }\end{array}$ & $\begin{array}{l}\text { Inactivation } \\
\text { by Strain }\end{array}$
\end{tabular}

Carbenicillin

MIC Ditch Plate Inactivation

$(\mu \mathrm{g} / \mathrm{ml}) \quad$ Result by Strain
Proteus mirabilis

Proteus mirabilis

Proteus mirabilis

Proteus mirabilis

Proteus morganii

Proteus morganii

Providencia

E. coli

E. coli

Klebsiella aerogenes

Klebsiella aerogenes

Bact. anitratum

Bact. anitratum

Serratia

Serratia

128
256
256
256
512
512
128
64
512
64
128
64
32
4
32

$\mathbf{R}$
$\mathbf{R}$
$\mathbf{R}$
$\mathbf{R}$
$\mathbf{R}$
$\mathbf{R}$
$\mathbf{R}$
$\mathbf{R}$
$\mathbf{R}$
$\mathbf{R}$
$\mathbf{R}$
$\mathbf{R}$
$\mathbf{R}$
$\mathbf{S}$
$\mathbf{R}$

$\begin{array}{rrr}- & 2 & \mathrm{~S} \\ + & 16 & \mathrm{~S} \\ + & 1024 & \mathrm{R} \\ + & 512 & \mathrm{R} \\ + & 512 & \mathrm{R} \\ + & 128 & \mathrm{R} \\ + & 128 & \mathrm{R} \\ + & 32 & \mathrm{R} \\ + & 2048 & \mathrm{R} \\ + & 32 & \mathrm{R} \\ + & 8192 & \mathrm{R} \\ + & 4 & \mathrm{~S} \\ + & 32 & \mathrm{R} \\ + & 32 & \mathrm{R} \\ + & 64 & \mathrm{R}\end{array}$

$\begin{array}{ll}\mathbf{S} & - \\ \mathbf{S} & - \\ \mathbf{R} & + \\ \mathbf{R} & - \\ \mathbf{R} & + \\ \mathbf{R} & - \\ \mathbf{R} & - \\ \mathbf{R} & - \\ \mathbf{R} & + \\ \mathbf{R} & - \\ \mathbf{R} & + \\ \mathbf{S} & - \\ \mathbf{R} & - \\ \mathbf{R} & - \\ \mathbf{R} & -\end{array}$

-
-
+
+
-
-
-
+
+
+
-
-
-

1
4
128
$0 \cdot 5$
256
8
4
16
256
128
256
16
8
8
16

$\begin{array}{ll}\text { S } & - \\ \mathbf{S} & - \\ \mathbf{R} & + \\ \mathbf{S} & - \\ \mathbf{R} & + \\ \mathbf{S} & - \\ \mathbf{S} & - \\ \mathbf{S} & - \\ \mathbf{R} & + \\ \mathbf{R} & - \\ \mathbf{R} & - \\ \mathbf{S} & - \\ \mathbf{S} & - \\ \mathbf{S} & - \\ \mathbf{S} & -\end{array}$

TYPES OF Ps. aeruginosa AND PROBABLE SOURCES OF INFECTION For six weeks, a selection of strains of $P$ s. aeruginosa from all patients whose burns were colonized by the organism were examined each week for serotype and phage type.

Each week between three and seven patients were found to have Ps. aeruginosa in their burns; sometimes two, three, or even four different types were isolated from one patient, and between three and seven types of $P$ s. aeruginosa were found in the ward each week. Each patient tended to go on carrying strains of the same type for two weeks or longer (Table VIII).

Self infection has been considered by some to be an important source of Ps. aeruginosa infection of burns (Sachs and Watson, 1969), but the relative rarity of $P s$. aeruginosa in the faeces of normal subjects (eg, Lowbury and Fox, 1954; Shooter, Walker, Williams, Horgan, Parker, Asheshov, and Bullimore, 1966) makes it seem more likely that infections are usually acquired from external sources. This view was supported by typing of $P$ s. aeruginosa in the Burns Unit (see also Lowbury and Fox, 1954), which showed that new infections were almost always due to types that had recently been isolated from other patients in the Unit, more often from patients in the same ward (Table IX). Of the strains which were not found in other patients before they were first detected in a burn, some may have been missed, because not all isolates of Ps. aeruginosa were typed. The data strongly support the view that cross infection is the usual mode of infection with Ps. aeruginosa in burns.

\section{DISCUSSION}

The proportions of different genera and species of aerobic Gram-negative bacilli isolated from burns were different from those normally found in the faeces. While the latter include a large preponderance of $E$. coli, the largest proportion of strains 
TABLE VII

PATTERNS OF RESISTANCE IN THE COMMONER SPECIES

\begin{tabular}{|c|c|c|}
\hline Species & $\begin{array}{l}\text { No. of } \\
\text { Strains }\end{array}$ & $\begin{array}{l}\text { Resistance Patterns Shown by } \\
\text { Numbers of Strains }\end{array}$ \\
\hline Proteus mirabilis & 59 & $\begin{array}{l}\text { AT (28), ATCe (7), AChT (6), } \\
\text { T and ATCaCe (4), AChTCe } \\
\text { and TCe (3), TCh, ATCa, } \\
\text { AKChT and ATCaKCe (1). }\end{array}$ \\
\hline Escherichia coli & 123 & $\begin{array}{l}\text { A (52), AT (22), ATCe (7), } \\
\text { ACaCe, ACe and ATCaCe (6) } \\
\text { ACa (5), AChTCaCe (4), T } \\
\text { and AKTCaCe (3), } \\
\text { ACh,AChT and AKCaCe (2), } \\
\text { Ce, AKT and AChTCa (1). }\end{array}$ \\
\hline Enterobacter aerogenes & 33 & $\begin{array}{l}\text { ATCe (12), ACe (9), A and } \\
\text { Ce (2), CeCa, T, TCe, ACa, } \\
\text { NACaTCe, ATCaCe, ATGCe } \\
\text { and ATCa (1). }\end{array}$ \\
\hline Enterobacter cloacae & 97 & $\begin{array}{l}\text { ACe and ATCe (38), A (8), } \\
\text { ATCaCe (4), AT (2), AChCe, } \\
\text { NAChTCe, Ce, AGCe, TCe, } \\
\text { NATCe and ACaCe (1). }\end{array}$ \\
\hline Klebsiella aerogenes & 22 & $\begin{array}{l}\mathrm{ACa}(8), \mathrm{ACaCe}(6), \mathrm{ATCa} \\
\text { and NAChTCa (2), } \\
\text { NAChCaCe, CaCe, ATCaCe } \\
\text { and ATChTCaCe (1). }\end{array}$ \\
\hline
\end{tabular}

$\mathrm{A}=$ ampicillin, $\mathrm{Ca}=$ carbenicillin, $\mathrm{Ce}$ cephaloridine, $\mathrm{Ch}-$ chloramphicol, $\mathrm{G}$ gentamicin, $\mathrm{K}=$ kanamycin, $\mathrm{N}-$ nalidixic acid, $\mathrm{T}=$ tetracycline

\section{TABLE VIII}

DURATION OF CARRIAGE OF SAME TYPES OF Ps. aeruginosa IN BURNS

Ward Numbers of Patients Carrying Same Types of Total Ps. aeruginosa for

One Two Three Four Five Six Six

Week Weeks Weeks Weeks Weeks Weeks Weeks

\begin{tabular}{lllllllll}
\hline $\mathrm{E}$ & 1 & 3 & 2 & 2 & 2 & 1 & 1 & 12 \\
$\mathrm{~F}$ & 1 & 3 & 4 & 1 & 1 & 0 & 0 & 10
\end{tabular}

TABLE IX

PREEXISTING INFECTION WITH $P$. aeruginosa IN BURNS WARD AS PROBABLE SOURCE OF NEW INFECTION DURING FOUR MONTHS

Patients in whom Infecting Types of Ps aeruginosa Were ${ }^{1}$ Previously Isolated from Not Previously Isolated from Other Patients $^{2} \quad$ Other Patients in Wards E or F In Ward E In Ward F

\begin{tabular}{lrrr}
\hline Ward E & 21 & 5 & 6 \\
Ward F & 3 & 17 & 7
\end{tabular}

${ }^{1}$ Patients acquiring more than one type of $P$ s. aeruginosa are represented separately for each type acquired. ${ }^{2}$ Within previous two months.

from burns were Proteus spp, of which $P$. mirabilis was by far the commonest species. In this respect the bacteria of burns resemble those of secondary infection of the urinary tract, which include a large proportion of strains, including Ps. aeruginosa, acquired from other patients or from environmental sources (Gould, 1968). Since Ps. aeruginosa is present in the faeces of a relatively small proportion of normal subjects, the high incidence of these bacteria commonly found in burns not specifically protected against them must be attributed to infection from sources outside the patient (Lowbury and Fox, 1954; Wahba, 1965); this view is supported by the presence, in most cases, of the infecting type in other patients before its first appearance in a burn. The relatively high incidence of Proteus spp and Klebsiella spp may be due, also, to frequent cross infection with these organisms, or it may be the selective result of poorer growth conditions for $E$. coli than for some other Gram-negative bacilli in the burn, while optimal conditions for $E$. coli are found in the colon. The typing of $E$. coli and other Gramnegative bacilli isolated from the faeces of patients on admission to hospital and subsequently from their burns should throw light on this problem.

The antibiotic sensitivity patterns of the strains isolated from burns support the view that a large proportion of these organisms is acquired in hospital. As in secondary urinary tract infection (Gould, 1968), a high proportion of $E$. coli isolated from burns were resistant to ampicillin. More surprising, perhaps, was the high incidence of ampicillinresistant Proteus mirabilis (cf Barber and Waterworth, 1964). This was probably the result of the extensive use of ampicillin in the treatment of patients in the Burns Unit. Tests on ampicillin-resistant strains preserved for 15 months showed some evidence of reversion to sensitivity, but a large proportion retained their resistance. Resistance of $P$. mirabilis to ampicillin is commonly associated with penicillinase production; it was therefore surprising that most of the ampicillin-resistant strains were sensitive to carbenicillin which, like ampicillin, is inactivated by penicillinase. Tests on inactivation of the antibiotics by penicillinase from 15 strains of Proteus and other organisms showed that those which inactivated ampicillin also inactivated carbenicillin; some strains were intrinsically resistant to ampıcillin without producing a penicillinase active against it, and these were sensitive to carbenicillin. As regards the other antibiotics, nalidixic acid, kanamycin, trimethoprim, and gentamicin were active against the largest number of strains.

Multiple resistance was commoner among strains of Klebsiella spp, Enterobacter spp, and Proteus mirabilis than among $E$. coli; this may have been due to the greater frequency of $E$. coli in the normal intestinal flora and may indicate a larger incidence of self-infection, as distinct from cross infection, with $E$. coli. A similar observation has been made in respect of urinary tract infection by Talbot, 
Cunliffe, and Gower (1957). A large proportion of strains of $E$. coli acquired by infants today have been shown to possess transferable antibiotic resistance (Moorhouse, 1969; Datta, 1969). It seems likely that many of the resistant strains found in our series were brought in by patients and had transferable resistance. Many burns become colonized by several different species of Gram-negative bacilli, which would provide opportunities for resistance to be transferred and to increase even when antibiotics are not used. It seems a likely cause for the high incidence of ampicillin-resistant Proteus mirabilis, most strains of which were distinct from each other by the Dienes reaction.

In the absence of data on typing of strains within species it is hard to assess the importance of different sources and routes of infection with Gram-negative bacilli. It was, however, possible to form an opinion on sources of infection with Ps. aeruginosa from the result of serological and phage typing. Most patients became infected with types previously found in other patients in the Unit, and especially in the same ward. Since $P$ s. aeruginosa is usually found to be a relatively rare member of the faecal flora of normal subjects, cross infection must be regarded as a much more important route of transfer with these organisms than self infection.

Tests with sulfamylon hydrochloride confirmed the activity of this agent, at the high concentrations $(10 \%)$ used for local prophylaxis, against a series of strains of Gram-negative bacilli from burns. Some strains, however, were inhibited only by concentrations as high as $2 \%$; the margin between the MIC and the concentration of antibacterial agent applied with success to burns is usually much greater. Some tests for synergy through combined action of sulfamylon with trimethoprim were made, because of the known synergy between sulphonamides and trimethoprim (Bushby and Hitchings, 1968). There appeared to be no synergic action against strains sensitive to trimethoprim, but appreciable synergy was found against some strains showing moderate resistance to trimethoprim, including Ps. aeruginosa and Enterobacter spp. In view of the known synergy of sulphadiazine with trimethoprim, the use of this combination for prophylaxis and therapy of Gramnegative bacillary infection in burns deserves study. Another combination which has been reported to have a valuable prophylactic effect is that of silver nitrate with sulphadiazine (Fox, 1968). Studies are in progress to determine, by controlled trial, the local chemoprophylactic effect of silver-sulphadiazine, silver nitrate-trimethoprim, and sulphadiazinetrimethoprim applications on burns.

We are grateful to Dr M. T. Parker and Mrs E. Asheshov of the Central Public Health Laboratory for the typing of many strains of Ps. aeruginosa.

\section{REFERENCES}

Barber, M., and Waterworth, P. M. (1964). Brit. med. J., 2, 344.

Brown, V. I., and Lowbury, E. J. L. (1965). J. clin. Path., 18, 752. Bushby, S. R. M. (1955). Ibid, 8, 120.

- , and Hitchings, G. H. (1968). Brit. J. Pharmacol., 33, 72

Cason, J. S., and Lowbury, E. J. L. (1968). Lancet, 1, 651.

- Jackson, D. M., Lowbury, E. J. L., and Ricketts, C. R. (1966). Brit. med.J., 2, 1288.

Colebrook, L., Clark, A. M., Gibson, T., Todd, J. P., Brown, A., and Anderson, A. B. (1944). Studies of Burns and Scalds. Spec. Rep. Ser. Med. Res. Coun. (Lond.), 249.

Cowan, S. T., and Steel, K. J. (1961). J. Hyg. (Lond.), 59, 357.

- (1965). Manual for the Identification of Medical Bacteria. Cambridge University Press, London.

Datta, N. (1969). Brit. med. J., 2, 407.

Finland, M. (1960). New Engl.J. Med., 263, 207.

Fox, C. L., Jr. (1968). Arch. Surg., 96, 184.

Gould, J. C. (1968). In Urinary Tract Infection, edited by F. O'Grady and W. Brumfitt, p. 43. Oxford University Press, London.

Hugh, R., and Leifson, E. (1953). J. Bact., 66, 24.

Jackson, D. M., Lowbury, E. J. L., and Topley, E. (1951). Lancet, 2, 137.

Jones, R. J., Jackson, D. M., and Lowbury, E. J. L. (1966). Brit. J. plast. Surg., 19, 43.

Kohn, J. (1953). J. clin. Path., 6, 249.

Kovacs, N. (1956). Nature (Lond.), 178, 703.

Langohr, J. L., Owen, C. R., and Cope, O. (1947). Ann. Surg., 125, 452.

Liedberg, N. C. F., Reiss, E., Kuhn, L. R., Amspacher, W. H., and Artz, C. P. (1955). Surg. Gynec. Obstet., 100, 219.

Lindberg, R. B., Moncrief, J. A., Switzer, W. E., Order, S. E., and Mills, W., Jr. (1965). J. Trauma, 5, 601.

Liston, J., Wiebe, W., and Colwell, R. R. (1963). J. Bact., 85, 1061.

Lowbury, E. J. L. (1960). Brit. med. J., 1, 994.

$\longrightarrow$, and Fox, J. (1954). J. Hyg. (Lond.), 52, 403.

, and Jackson, D. M. (1968). Lancet, 1, 654.

(1969). Injury, 1 , in press.

, Lilly, H. A., and Wilkins, M. D. (1962). J. clin. Path., 15, 339.

_, Thom, B. T., Lilly, H. A., Babb, J. R., and Whittall, K. (1969). J. med. Microbiol., in press.

Markley, K., Gurmendi, G., Chavez, P. M., and Bazan, A. (1957). Ann. Surg., 145, 175.

Møller, V. (1955). Acta path. microbiol. scand., 36, 158.

Moorhouse, E. C. (1969). Brit. med. J., 2, 405.

Rogers, K. B., and Taylor, J. (1961). Bull. World Hlth Org., 24, 59.

Sachs, A., and Watson, J. (1969). Lancet, 1, 718.

Shaw, C., and Clarke, P. H. (1955). J. gen. Microbiol., 13, 155.

Shooter, R. A., Walker, K. A., Williams, V. R., Horgan, G. M., Parker, M. T., Asheshov, E. H., and Bullimore, J. F. (1966). Lancet, 2, 1331 .

Talbot, J. M., Cunliffe, A. C., and Gower, N. D. (1957). J. clin. Path., $10,222$.

Topley, E., Lowbury, E. J. L., and Hurst, L. (1951). Lancet, 1, 87.

Tumbusch, W. T., Vogel, E. H., Jr., Butkiewicz, J. V., Graber, C. D., Larson, D. L., and Mitchell, E. T., Jr. (1961). J. Trauma, 1, 22.

Wahba, A. H. (1965). Brit. med. J., 1, 86.

Watt, P. J., and Okubadejo, O. A. (1967). Ibid, 1, 210. 
a low production of pigment on normal media, according to all the other biochemical tests showed them to be normal $P$. aeruginosa strains; this was confirmed by the results of the growth on the milk agar, both hydrolysis of the casein and pigment production being observed. In the case of the other two strains, 950 and 5940, the position was not so straightforward. Neither produced pigment on any of the solid media, including the milk agar. They did, however, show some signs of hydrolysis of the casein, and this increased on incubation for a further 48 hours, but no pigment was demonstrable. The results of the biochemical tests likewise showed that these two strains did not conform precisely to the $\boldsymbol{P}$. aeruginosa or the $\boldsymbol{P}$. fluorescens patterns, but in fact have some characters common to both, and these can be regarded as intermediate fluorescens/aeruginosa types. This is supported by the results of the milk agar media previously discussed. Indeed, in view of the recently demonstrated high transformation frequency within the genus Pseudomonas (Khan and Sen, 1967), the existence of such intermediate strains is not surprising. In either case, the milk agar has shown itself to be as reliable as the more conventional biochemical tests.

We wish to thank Dr S. P. Lapage, of the National Collection of Type Cultures, for kindly supplying the poorly pigmented strains of $P$. aeruginosa, and Dr M. T. Parker, of Central Public Health Laboratory, Colindale, London, NW9, for kindly carrying out the phage typing. We also wish to thank The Medical Research Council for a grant which supported part of this work.

\section{References}

Colwell, R. R. (1964). J. gen. Microbiol., 37, 181-194. A study of features used in the diagnosis of Pseudomonas aeruginosa.

Cowan, S. T., and Steel, K. J. (1965). Manual for the Identification of Medical Bacteria. Cambridge University Press, London.

Gaby, W. L., and Free, E. (1953). Occurrence and identification of nonpigmented strains of Pseudomonas aeruginosa in the clinical laboratory. J. Bact., 65, 746.

Gaby, W. L, and Free, E. (1958). Differential diagnosis of Pseudomonas-like microorganisms in the clinical laboratory. J. Bact., 76, 442-444

Haynes, W. C. (1951). Pseudomonas aeruginosa-its characterisation and identification. J. gen. Microbiol., 5, 939-950.

Hugh, R., and Leifson, E. (1953). The taxonomic significance of fermentative versus oxidative metabolism of carbohydrates by various gram negative bacteria. J. Bact., 66, 24-26.

Khan, N. C., and Sen, S. P. (1967). Genetic transformation in Pseudomonas. J. gen. Microbiol., 49, 201-209.

King, E O., Ward, M. K., and Raney, D. E. (1954). Two simple media for the demonstration of pyocyanin and fluorescin. J. Lab. clin. Med., 44, 301-307.

Kovacs, N. (1956). Identification of Pseudomonas pyocyanea by the oxidase reaction. Nature (Lond.), 178, 703.

Lysenko, O. (1961). Pseudomonas-An attempt at a general classification. J. gen. Microbiol., 25, 379-408.

Phillips, I. (1969). Identification of Pseudomonas aeruginosa in the clinical laboratory. J. Med. Microbiol., 2, 9-16.

Preston, N. W., and Morrell, A. (1962). Reproducible results with the gram stain. J. Path. Bact., 84, 241-243.
Rhodes, M. E. (1959). The characterization of Pseudomonas fluorescens. J. gen. Microbiol., 21, 221-263.

Rhodes M. E., (1961). The characterization of Pseudomonas fluorescens with the aid of an electronic computer. J. gen. Microbiol., 25, 331-345

Rogers, K. B. (1963). Oxidase reaction. (Letter), Lancet, 2, 682.

Stanier, R. Y., Palleroni, N. J., and Disudoroff, M. (1966). The aerobic psuedomonads: a taxonomic study. J. gen. Microbiol., 43, 159-271.

Wahba, A. H., and Darell, J. H. (1965). The identification of atypical strains of Pseudomonas aeruginosa. J. ger. Microbiol., 38, 329-342.

\section{Errata}

In Table II in the paper entitled, 'Comparison of quick and slow thaw methods of producing cryoprecipitate antihaemophilic factor from fresh and 24-hour-old blood' A. L. Bloom (J. clin. Path., 22, 447-452) the $P$ values for the supernatant have been printed under the wrong headings. The correct table 'Factor VIII content of cryoprecipitate and supernatant plasma', is printed below.

\begin{tabular}{|c|c|c|c|c|}
\hline & \multicolumn{2}{|c|}{ Fresh Blood } & \multicolumn{2}{|c|}{$\begin{array}{l}\text { Twenty-four Hour } \\
\text { Blood }\end{array}$} \\
\hline & $\begin{array}{l}\text { Quick- } \\
\text { Thaw } \\
\text { (A) }\end{array}$ & $\begin{array}{l}\text { Slow- } \\
\text { Thaw } \\
\text { (B) }\end{array}$ & $\begin{array}{l}\text { Quick- } \\
\text { Thaw } \\
\text { (C) }\end{array}$ & $\begin{array}{l}\text { Slow- } \\
\text { Thaw } \\
\text { (D) }\end{array}$ \\
\hline Number of sample & 101 & 67 & 102 & 76 \\
\hline $\begin{array}{l}\text { Factor VIII in } \\
\text { cryoprecipitate } \\
\text { units) Mean } \pm S D\end{array}$ & $83 \pm 32$ & $112 \pm 44$ & $53 \pm 25$ & $72 \pm 30$ \\
\hline $\begin{array}{l}\text { Factor VIII in } \\
\text { supernatant (units) } \\
\text { Mean } \pm \text { SD }\end{array}$ & $42 \pm 21$ & $30 \pm 21$ & $31 \pm 19$ & $25 \pm 12$ \\
\hline $\begin{array}{l}\text { Statistical } \\
\text { significance }\end{array}$ & $A \cup B$ & $C \vee D$ & $C$ & $D$ \\
\hline Supernatant & $P=<0.001$ & $P=<0.001$ & & \\
\hline Cryoprecipitate & $P=<0.001$ & $P=<0.001$ & $<0.001$ & $=<0.001$ \\
\hline
\end{tabular}

In Table IIa of the paper by Davis et al, J. Clin. Path., 1969, 22, 634, the figures for Proteus mirabilis under the columns for tetracycline should read: S: $9.7 \%$, 'S': $0.9 \%$ and $R: 89.4 \%$; the mean percentages of total should therefore read: $S: 30.8 \%$; 'S': $6 \cdot 1 \%$; R: $63 \cdot 1 \%$. 